\title{
Relationship between epicardial adipose tissue, coronary artery disease and adiponectin in a Mexican population
}

Teresa G Yañez-Rivera ${ }^{1 \dagger}$, Manuel A Baños-Gonzalez ${ }^{2,3 \dagger}$, Jorge L Ble-Castillo ${ }^{3 *}$, Manuel E Torres-Hernandez ${ }^{2 \dagger}$, Jorge E Torres-Lopez ${ }^{3+}$ and Gabriela Borrayo-Sanchez ${ }^{4+}$

\begin{abstract}
Background: The amount of epicardial adipose tissue (EAT) around the heart has been identified as an independent predictor of coronary artery disease (CAD), potentially through local release of inflammatory cytokines. Ethnic differences have been observed, but no studies have investigated this relationship in the Mexican population. The objective of the present study was to evaluate whether a relationship exist between EAT thickness assessed via echocardiography with CAD and adiponectin levels in a Mexican population.

Methods: We studied 153 consecutive patients who underwent coronary angiography and transthoracic echocardiography (TTE). EAT thickness on the free wall of the right ventricle was measured at the end of systole from parasternal long and short axis views of three consecutive cardiac cycles. Coronary angiograms were analyzed for the presence, extent and severity of CAD. Serum adiponectin, lipids, glucose, C-reactive protein and fibrinogen were determined.

Results: EAT thickness was greater in patients with CAD than in those without CAD from both parasternal long $(5.39 \pm 1.75 \mathrm{~mm}$ vs $4.00 \pm 1.67 \mathrm{~mm} p<0.0001)$ and short-axis views $(5.23 \pm 1.67$ vs $4.12 \pm 1.77, p=0.001)$. EAT thickness measured from parasternal long and short-axis showed a statistically significant positive correlation with age $(r=0.354, p<0.001 ; r=0.286, p<0.001$ respectively), and waist circumference $(r=0.189, p=0.019 ; r=0.217$, $p=0.007$ respectively). A significant negative correlation between EAT thickness from the parasternal long axis with cholesterol-HDL was observed $(r=-0.163, p=0.045)$. No significant correlation was found between epicardial fat thickness and serum adiponectin or with the severity of CAD.
\end{abstract}

Conclusions: EAT thickness was greater in patients with CAD. However, no correlation was observed with the severity of the disease or with serum adiponectin levels. EAT thickness measured by echocardiography might provide additional information for risk assessment and prediction of CAD.

Keywords: Epicardial adipose tissue, Coronary artery disease, Echocardiography, Adiponectin

\section{Background}

Obesity is the most prevalent risk factor for coronary artery disease [1]. Regional body adipose tissue distribution, rather than total body adiposity, is a known marker for cardiovascular risk [2]. A variety of pro and antiinflammatory mediators are expressed and secreted from

\footnotetext{
* Correspondence: jblecastillo@hotmail.com

${ }^{\dagger}$ Equal contributors

${ }^{3}$ Centro de Investigación y Posgrado, DACS, Universidad Juárez Autónoma de Tabasco (UJAT), Villahermosa, Tabasco, Mexico

Full list of author information is available at the end of the article
}

adipose tissue and have been demonstrated to participate in the various stages of atherogenesis [3]. Adiponectin is exclusively identified in mature adipocytes and decreased plasma levels are associated with atherosclerosis [4]; adiponectin levels are inversely correlated with the amount of visceral adipose tissue and may serve as a predictive factor for cardiovascular risk $[5,6]$. Epicardial adipose tissue (EAT) locally expresses adiponectin protein, with significantly lower levels in patients with coronary artery disease (CAD) [7-9].

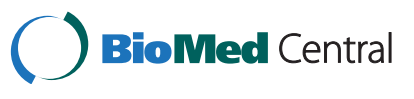

(C) 2014 Yañez-Rivera et al.; licensee BioMed Central Ltd. This is an Open Access article distributed under the terms of the Creative Commons Attribution License (http://creativecommons.org/licenses/by/4.0), which permits unrestricted use, distribution, and reproduction in any medium, provided the original work is properly credited. The Creative Commons Public Domain Dedication waiver (http://creativecommons.org/publicdomain/zero/1.0/) applies to the data made available in this article, unless otherwise stated. 
EAT is considered as visceral fat deposited around the heart, particularly around epicardial coronary vessels. Because of its proximity to the myocardium and absence of fascia, epicardial fat may directly affect the coronary arteries and myocardium through paracrine actions of locally secreted adipocytokines and other bioactive molecules, contributing to the development of CAD $[7,10,11]$.

Recently, a meta-analysis demonstrated that EAT thickness is an effective marker for predicting CAD [12]. However, several studies have shown that race can affect the distribution of intra-abdominal adipose tissues [13], and also participate in the observed differences in EAT thickness $[14,15]$. Mexico exhibits the highest obesity prevalence in the world, even so, to our knowledge there are no published studies on EAT thickness related to CAD and adiponectin. Thus, the present study was designed to assess whether an association exists between epicardial adipose tissue measured by transthoracic echocardiography with CAD and serum adiponectin in a Mexican population.

\section{Methods \\ Patients}

From February 2011 to June 2013, we conducted a crosssectional study on all patients admitted for elective coronary angiography for suspected coronary artery disease.

For all subjects, clinical data and anthropometric measures were recorded. Individuals were considered as type 2 diabetic if they had been previously diagnosed, were receiving hypoglycemic treatment and/or insulin, or had a fasting glucose level of $>126 \mathrm{mg} / \mathrm{dl}$ on two or more occasions. Hypertension was defined as systolic blood pressure $\geq 140 \mathrm{mmHg}$, diastolic blood pressure $>90$ $\mathrm{mmHg}$ or if previously diagnosed or receiving a previously established antihypertensive therapy. Hyperlipidemia was defined as a total cholesterol (TC) $\geq 200 \mathrm{mg} /$ dl, Low-density lipoprotein cholesterol (LDL-cholesterol) greater than $\geq 160 \mathrm{mg} / \mathrm{dl}$, triglycerides (TG) $\geq 150$ $\mathrm{mg} / \mathrm{dl}$ and/or a previous diagnosis or treatment. Decreased levels of high-density lipoprotein cholesterol (HDL-C) were defined as $<40 \mathrm{mg} / \mathrm{dl}$. Patients were considered smokers if they had smoked five or more cigarettes a day and had suspended this habit for longer than one year. Body mass index (BMI) was calculated by a standard formula [weight $(\mathrm{kg}) /$ height $(\mathrm{m})^{2}$ ]. Central obesity was considered if the waist circumference was $\geq 90 \mathrm{~cm}$ in men and $\geq 80 \mathrm{~cm}$ in women [16]. Patients with more than three of five criteria based on the International Diabetes Federation (IDF) were considered to have metabolic syndrome (MS). Patients were excluded if they had any of the following: chronic renal and/or hepatic disease, history of prior revascularization, patients with pericardial effusion and whose transthoracic echocardiographic imaging was inadequate for the measurement of epicardial fat thickness. Mexican Social Security Institute
(IMSS) Research Committee approved the study protocol, and all patients gave written informed consent.

\section{Laboratory measurements}

Blood samples were obtained after a fast of at least $8 \mathrm{~h}$. Serum and plasma were immediately distributed in aliquots and frozen at $-70^{\circ} \mathrm{C}$ for less than six months. The samples were analyzed in blocks to reduce inter-assay variability. Glucose concentrations, plasma lipid profile and high sensitivity C-reactive protein (hsCRP) were measured using the Architect Clinical Chemistry Autoanalyzer System from Abbott Clinical Chemistry (Chicago, IL, USA). The assay reliability of these parameters was $<5 \%$ coefficient of variation. Fibrinogen determination was performed using ACL Elite Pro equipment with the Clauss method. Plasma concentrations of adiponectin were determined using a commercially available immunoassay kit SPI-bio Bertin Pharma (Montigny le Bretonneux, France) and the values were expressed in $\mu \mathrm{g} / \mathrm{ml}$.

\section{Evaluation of epicardial adipose tissue}

Two-dimensional transthoracic echocardiography (Philips iE33, with 3.5 MHz transducer) in the left lateral decubitus position was performed. Measurements were performed by a cardiologist who was unaware of angiographic data. Epicardial adipose tissue was identified as echo-free space in the pericardial layers on the two-dimensional echocardiography and its thickness was measured perpendicularly on the free wall of the right ventricle at the end of systole, repeated over three cardiac cycles. Two standard echocardiographic windows, parasternal long-axis and short-axis, were used. A pre-specified anatomical reference for each echocardiographic window was considered as a standard measurement point in order to be consistent with other studies. For the parasternal long axis view, the anatomical reference was the aortic annulus. Measurements were performed at the point on the right ventricular free wall in the midline with the ultrasound beam, perpendicular to the aortic annulus. For the parasternal short axis view, epicardial adipose tissue thickness was measured on the right ventricular free wall, $2 \mathrm{~cm}$ from the ventricular septum. We calculated an average value of three cardiac cycles for each echocardiographic window for statistical analysis. Echocardiographic measurement of epicardial thickness was defined as an epicardial thickness $>1 \mathrm{~mm}$ in at least one acoustic window. The reliability of transthoracic echocardiography for measuring EAT thickness, has been confirmed by its good correlation with magnetic resonance imaging [17].

\section{Coronary artery occlusion assessment}

Selective coronary angiography was performed using femoral access in all patients. Patients were classified as $\mathrm{CAD}+$, defined as $>50 \%$ stenosis in at least one major 
coronary artery, or CAD - with no angiographic evidence of significant coronary artery occlusion. Severity of coronary atherosclerosis was classified as 1-, 2-, or 3-vessel disease according to the number of stenotic major coronary arteries (left anterior descending artery, circumflex artery and right coronary artery).

\section{Statistical analysis}

We used descriptive statistics with mean \pm SD or median with interquartile range values in accordance with their distribution. Student's $t$-test or Mann-Whitney tests were performed to compare the differences between continuous variables according to their distribution. Significant differences between categorical variables were evaluated using a Chi-square test. The Pearson or Spearman correlation tests were used to evaluate an association of EAT and adiponectin with other quantitative variables. Multiple logistic regression analysis was used to estimate the association between variables and the presence or absence of CAD. In order to determine the predictive value of EAT thickness and adiponectin levels multiple logistic regression analysis was applied to these variables as well as the other factors including conventional clinical variables. In this model, those variables that showed $\mathrm{p}$ values $<0.05$ in the univariate analysis were included. Odds ratios and 95\% confidence intervals (CIs) for CAD + vs CAD- were calculated. A value of $p<0.05$ was considered to be statistically significant. Analyses were performed using SPSS, version 15 (Chicago, IL, USA).

To assess the reproducibility of echocardiographic measurements of epicardial adipose tissue, 24 patients were randomly selected for off-line analysis by two observers who were unaware of clinical and angiographic data and inter-observer correlation coefficients were calculated. In the same group of patients, echocardiographic measurements were repeated two days later to calculate intraobserver correlation coefficients.

\section{Results}

\section{Clinical characteristics}

Clinical and laboratory data of 153 patients with or without CAD are summarized in Table 1. Our patient cohort consisted of 119 subjects with CAD (77.7\%) and 34 subjects without CAD (22.2\%). Male gender was more predominant in the CAD + group $(\mathrm{p}<0.001)$. Compared to those without significant stenosis, patients with $\mathrm{CAD}$ had higher waist-hip ratio $(0.98 \pm 0.06$ vs $0.917 \pm 0.08, \mathrm{p}<0.001)$, showed a higher $\mathrm{C}$-reactive protein $(3.01 \pm 5.65 \mathrm{vs} .1 .08 \pm 2.08 \mathrm{mg} / \mathrm{dl}, \mathrm{p}=0.002)$ and a lower HDL cholesterol level $(42.35 \pm 11.35$ vs. $35.81 \pm$ $8.94 \mathrm{mg} / \mathrm{dl}, \mathrm{p}=0.003)$. The ejection fraction measured by echocardiography was similar between the CAD- and CAD + groups.
Table 1 Clinical and laboratory characteristics in patients with and without coronary artery disease

\begin{tabular}{|c|c|c|c|}
\hline & CAD- $(n=34)$ & $C A D+(n=119)$ & $\mathrm{p}$ value \\
\hline Age (years) & $59.18 \pm 12.25$ & $61.76 \pm 10.05$ & 0.210 \\
\hline $\begin{array}{l}\text { Male gender, } \\
\text { n (\%) }\end{array}$ & $14(41.1)$ & $98(82.3)$ & $<0.001$ \\
\hline BMI $\left(\mathrm{kg} / \mathrm{m}^{2}\right)$ & $30.74 \pm 5.90$ & $28.92 \pm 3.87$ & 0.198 \\
\hline $\begin{array}{l}\text { Central obesity } \\
\mathrm{n}(\%)\end{array}$ & $33(97.0 \%)$ & 118 (99.1\%) & 0.791 \\
\hline WC (cm) & $100.97 \pm 11.81$ & $103.47 \pm 8.81$ & 0.256 \\
\hline Waist-hip ratio & $0.92 \pm 0.08$ & $0.98 \pm 0.06$ & $<0.001$ \\
\hline Smoking, n (\%) & $6(17.6)$ & $64(53.7)$ & $<0.001$ \\
\hline $\begin{array}{l}\text { Diabetes mellitus, } \\
\mathrm{n}(\%)\end{array}$ & $13(38.2)$ & $65(54.6)$ & 0.093 \\
\hline $\begin{array}{l}\text { Hypertension, } \\
\text { n (\%) }\end{array}$ & $26(76.5)$ & $85(71.4)$ & 0.564 \\
\hline $\begin{array}{l}\text { Hyperlipidemia, } \\
\text { n (\%) }\end{array}$ & $24(70.5)$ & $85(71.4)$ & 0.924 \\
\hline $\begin{array}{l}\text { Metabolic } \\
\text { syndrome n (\%) }\end{array}$ & $29(85.2)$ & $111(93.2)$ & 0.141 \\
\hline FPG (mg/dl) & $104.0(95.00-119.25)$ & $119.5(97.00-152.25)$ & 0.076 \\
\hline $\begin{array}{l}\text { Total cholesterol } \\
(\mathrm{mg} / \mathrm{dl})\end{array}$ & $175.97 \pm 41$ & $164.94 \pm 48.55$ & 0.231 \\
\hline LDL-C (mg/dl) & $103.85 \pm 33.58$ & $91.63 \pm 37.33$ & 0.088 \\
\hline $\mathrm{HDL}-\mathrm{C}(\mathrm{mg} / \mathrm{dl})$ & $42.35 \pm 11.35$ & $35.81 \pm 8.94$ & 0.003 \\
\hline TG (mg/dl) & $141(106.5-203.5)$ & $151(105.0-245.0)$ & 0.353 \\
\hline $\mathrm{hsCRP}(\mathrm{mg} / \mathrm{dl})$ & $1.08 \pm 2.08$ & $3.01 \pm 5.65$ & 0.002 \\
\hline $\begin{array}{l}\text { Adiponectin } \\
(\mu \mathrm{g} / \mathrm{ml})\end{array}$ & $11.66 \pm 6.77$ & $8.88 \pm 4.64$ & 0.039 \\
\hline $\begin{array}{l}\text { Fibrinogen } \\
\text { (mg/dl) }\end{array}$ & $547.0(469.0-660.0)$ & 591.5 (480.5-744.0) & 0.090 \\
\hline
\end{tabular}

Data are expressed as number and $\%$ of patients, mean \pm SD or median $\left(25^{\text {th }}\right.$, $75^{\text {th }}$ percentiles). CAD - Coronary artery disease; BMI - Body mass index; WC - Waist circumference; FPG - fasting plasma glucose; LDL-C - low-density lipoprotein cholesterol; HDL-C - high-density lipoprotein cholesterol; TG triglycerides; hsCRP - high sensitivity C-reactive protein. Central obesity was defined as increased waist circumference.

\section{EAT thickness and coronary artery disease}

Inter-observer and intra-observer correlation coefficients of EAT thickness measurements were 0.96 and 0.94 respectively, indicating excellent reproducibility of echocardiographic measurements. Mean values of epicardial adipose tissue thickness from the parasternal long and short axes views in all patients were $5.08 \pm 1.82$ and $4.99 \pm 1.75 \mathrm{~mm}$, respectively. Forty-eight (31.4\%) patients had single vessel, $36(23.5 \%)$ two vessels and 35 $(22.9 \%)$ had three vessels with $>50 \%$ of stenosis. Table 2 shows the echocardiographic data. EAT was thicker in patients with CAD than in those without CAD in both the parasternal long axis $(5.39 \pm 1.75$ vs $4.00 \pm 1.67 \mathrm{~mm}$, $\mathrm{p}<0.0001)$ and short axis $(5.23 \pm 1.67$ vs $4.12 \pm 1.77 \mathrm{~mm}$, $\mathrm{p}=0.001)$ views. 
Table 2 Echocardiographic findings in patients with and without coronary artery disease

\begin{tabular}{lccc}
\hline & CAD- $(\mathbf{n}=\mathbf{3 4})$ & CAD $+(\mathbf{n}=\mathbf{1 1 9})$ & $\mathbf{p}$ value \\
\hline EAT PLX $(\mathrm{mm})$ & $4.00 \pm 1.67$ & $5.39 \pm 1.75$ & $<0.0001$ \\
EAT PSX $(\mathrm{mm})$ & $4.12 \pm 1.77$ & $5.23 \pm 1.67$ & 0.001 \\
\hline
\end{tabular}

EAT - epicardial adipose tissue; PLX - parasternal long-axis view, PSX parasternal short-axis view.

\section{Association of epicardial adipose tissue with various clinical, biochemical and angiographic variables}

Table 3 shows the correlations of EAT with clinical, biochemical and angiographic variables. EAT thickness measured from the long and short axes showed a significant positive correlation with age $(\mathrm{r}=0.354, \mathrm{p}<0.001$ and $\mathrm{r}=0.286, \mathrm{p}<0.001$ respectively); with waist circumference $(\mathrm{r}=0.214, \mathrm{p}=0.008$ and $\mathrm{r}=0.234, \mathrm{p}=0.004)$; with waist-hip ratio $(\mathrm{r}=0.189, \mathrm{p}=0.019$ and $\mathrm{r}=0.217$, $\mathrm{p}=0.007)$; with waist-height ratio $(\mathrm{r}=0.243, \mathrm{p}=0.002$ and $r=0.267, p=0.001$ ). EAT thickness was inversely correlated with the level of high-density lipoprotein cholesterol $(\mathrm{r}=-0.163, \mathrm{p}=0.045)$. Eighty-five percent of subjects in the CAD- group and $92 \%$ in the CAD + group had MS (Table 1). No significant differences were observed in EAT thickness between patients with MS and without MS in the parasternal long axis $(5.05 \pm 1.83$ vs $5.38 \pm 1.74 \mathrm{~mm}$, $\mathrm{p}=0.539)$ and parasternal short axes $(4.99 \pm 1.75$ vs $4.97 \pm 1.82 \mathrm{~mm}, \mathrm{p}=0.970$ ), respectively. There was no significant correlation between echocardiographic epicardial

Table 3 Univariate correlations between cardiac adipose tissue thickness and clinical variables

\begin{tabular}{|c|c|c|c|c|}
\hline & $\begin{array}{c}\text { EAT PLX } \\
r\end{array}$ & $p$ value & $\begin{array}{c}\text { EAT PSX } \\
r\end{array}$ & $p$ value \\
\hline Age & 0.354 & $<0.001$ & 0.286 & $<0.001$ \\
\hline Height & -0.004 & 0.958 & 0.000 & 0.997 \\
\hline Weight & -0.023 & 0.780 & -0.004 & 0.963 \\
\hline Body surface area & -0.009 & 0.911 & -0.003 & 0.972 \\
\hline BMI & 0.049 & 0.552 & 0.070 & 0.389 \\
\hline Waist & 0.214 & 0.008 & 0.234 & 0.004 \\
\hline Hip & 0.097 & 0.231 & 0.107 & 0.187 \\
\hline WHR & 0.189 & 0.019 & 0.217 & 0.007 \\
\hline WHeR & 0.243 & 0.002 & 0.267 & 0.001 \\
\hline Total cholesterol & -0.008 & 0.919 & -0.057 & 0.481 \\
\hline HDL-C & -0.163 & 0.045 & -0.139 & 0.087 \\
\hline LDL-C & -0.032 & 0.637 & 0.096 & 0.245 \\
\hline Glucose & 0.118 & 0.148 & 0.060 & 0.462 \\
\hline hsCRP & 0.125 & 0.124 & 0.110 & 0.176 \\
\hline Fibrinogen & 0.132 & 0.107 & 0.137 & 0.094 \\
\hline Adiponectin & -0.092 & 0.257 & -0.073 & 0.368 \\
\hline Number of stenotic vessels & 0.004 & 0.963 & 0.028 & 0.763 \\
\hline
\end{tabular}

adipose tissue thicknesses and the number of stenotic vessels.

\section{Relationship between adiponectin, CAD and epicardial adipose tissue}

Serum adiponectin levels were significantly lower in patients with CAD $(11.66 \pm 6.77$ vs $8.88 \pm 4.64 \mu \mathrm{g} / \mathrm{ml}, \mathrm{p}=$ $0.039)$. However, no significant correlations were found between EAT thickness obtained from the long- or short-axes and serum adiponectin (Table 3). Moreover, adiponectin levels in this sample were not a predictor of CAD (Table 4).

\section{Epicardial adipose tissue as a predictor of coronary artery disease}

Table 4 shows the results of the multivariate logistic regression analysis. Those variables that showed significant differences in the univariate analysis were selected for the multivariate analysis for the prediction of CAD. EAT thickness was found to be an independent predictor of obstructive CAD in addition to the well-known CAD risk factors such as male gender, $\mathrm{C}$-reactive protein and low HDL cholesterol.

\section{Discussion}

This study indicates that in a Mexican population, EAT thickness is associated with CAD. Multiple logistic analyses of several CAD risk factors suggested that EAT is an independent factor associated with CAD. This finding is consistent with others reports in different populations. Ahn et al. [18], reported this relationship in a subset of Korean patients. A recent meta-analysis showed that EAT may be an effective marker for the prediction of coronary heart disease [12]. In our study, mean EAT thickness in patients with coronary heart disease was $5.2 \mathrm{~mm}$, similar to values reported by Mustelier et al. [19], in another Hispanic population. This value is lower than others found in Japanese and USA populations [20,21], but higher than in the Korean population [18].

Table 4 Multiple logistic regression analysis for the prediction of significant coronary artery disease

\begin{tabular}{lcc}
\hline & OR $(\mathbf{9 5} \% \mathrm{Cl})$ & p value \\
\hline Male & $14.182(3.877-51.876)$ & $<0.0001$ \\
WHR & $0.952(0.921-0.985)$ & 0.004 \\
Smoking & $3.385(1.064-10.767)$ & 0.039 \\
HDL-C & $0.992(0.943-1.044)$ & 0.761 \\
hsCRP & $1.165(0.979-1.385)$ & 0.085 \\
Adiponectin & $0.977(0.898-1.063)$ & 0.583 \\
EAT thickness & $1.903(1.366-2.653)$ & $<0.0001$ \\
\hline
\end{tabular}

WHR - waist-hip ratio; HDL-C - high-density lipoprotein cholesterol; hsCRP high sensitivity C-reactive protein; EAT - epicardial adipose tissue. 
EAT thickness may be different according to ethnic group. Several studies have shown that ethnicity affects the distribution of visceral adipose tissue. Willens et al. [14], showed that non-Hispanic white males have larger epicardial fat thickness than African-American men, independently of age, weight, and BMI. These differences might be attributed to inherited and nongenetic factors. However, the identities of genes that underlie population variation in adipose tissue development in humans are poorly understood.

The prevalence of obesity has increased worldwide, including in Mexico. Data from the national health and nutrition survey conducted in 2012 showed that obesity affects 7 in 10 Mexican adults [22]. This condition is a prominent risk factor for the development of chronic diseases, such as CAD. Obesity has a strong genetic contribution, in addition to already known environmental and nutritional factors. Our results showed that EAT thickness was significantly correlated with abdominal circumference, but not with BMI. Previous authors have shown similar findings [21]. A partial explanation is that BMI may not predict total adiposity. Although it is known that there are differences in the fat distribution between males and females, in this study a gender analysis was not possible because there were a limited number of women included in the CAD group.

In the present study, no relationship was observed between EAT thickness and the extent of CAD. This result agrees with previous findings from Mustelier et al. [19], but is in contrast with others $[18,23]$. The lack of association in this study could be partially attributed to the fact that EAT measurements are not performed at a specific anatomical site where the coronary stenosis is located. Moreover, a larger sample size could be needed in order to find this relationship. In this line, the extent of CAD could be related with other risk factors or with the existence of other metabolic disturbances.

Mechanisms that promote the development of CAD through epicardial fat are not completely clear. The role of epicardial fat as a metabolically active organ with paracrine or endocrine functions is the most accepted. Previous studies have shown that adipose tissue, particularly visceral fat, express numerous genes related to adipokine production, which have important roles in the development of atherosclerosis in obese patients [7,24]. Epicardial fat located near to the coronary tree could facilitate the paracrine effects of epicardial adipokines, as part of the pathogenesis of CAD $[11,25]$.

Few studies have evaluated the relationship between EAT thickness and serum adiponectin levels. Yun et al. [26], found a significant inverse relationship between EAT thickness and plasma adiponectin levels in patients with angina. Our data show that patients with CAD have significantly lower adiponectin levels compared to non-CAD subjects, but a significant correlation between EAT thickness and adiponectin was not observed. Furthermore, multivariate analyses did not show adiponectin as an independent variable for CAD risk.

While some studies have related epicardial fat with the presence of inflammatory markers, a direct relationship between these and EAT thickness or CAD has not been demonstrated. Iacobellis et al. [12], reported that protein expression of adiponectin from EAT in patients with extensive $C A D$ was significantly lower than non-CAD subjects; however, if the local adiponectin is produced in EAT rather than systemic influences on coronary heart disease is still debatable $[27,28]$. Further studies are needed in order to clarify the relation of adiponectin with coronary atherosclerosis.

Imaging studies demonstrated good accuracy for the quantification of adipose tissue in various body compartments, with a good correlation [15]. Transthoracic echocardiography provides a reliable measurement of epicardial adipose tissue thickness. This method has been validated with magnetic resonance imaging [17], which is currently the gold standard method and a widely accepted reference standard to measure visceral adiposity.

Echocardiography as a non-invasive method that is low in cost and widely available could be routinely performed in high-risk patients for the evaluation of epicardial adipose tissue and predicting CAD.

To the best of our knowledge, this is the first study to evaluate an association between EAT thickness, CAD and adiponectin in a Mexican population. Future studies are required to determine reference ranges and cut-off points for EAT thickness measured by echocardiography in Mexican population.

\section{Study limitations}

The present study has several limitations. 1. This crosssectional study cannot determine causal relationships between studied variables 2 . The sample size is modest for association studies. In the studied population, most patients who underwent coronary catheterization have a high risk for $\mathrm{CAD}$, but only a few patients had normal coronary arteries, so we had an unbalanced sample. However, coronary angiography is an invasive study with risks of complications, only indicated in patients with suspected ischemic heart disease and it would not have been ethical to perform it in healthy patients.

\section{Conclusions}

In this study, we observed an association of epicardial fat thickness measured by echocardiography with atherosclerotic CAD, but not with the degree of severity of the disease, or with serum levels of adiponectin. Echocardiography may provide additional information for predicting the risk of CAD in Mexican population. 


\section{Competing interests}

The authors declare that they have no competing interests.

\section{Authors' contributions}

TGYR carried out the ultrasound examinations and was involved in study design and drafting. MABG helped to perform the statistical analysis and draft the manuscript. JLBC was involved in study design and drafted the manuscript. METH carried out the angiography readings and was involved in drafting. JETL participated in the design and helped to draft the manuscript. GBS were involved in statistical analysis and drafting. All authors contributed equally. All authors read and approved the final manuscript.

\section{Acknowledgements}

This work was part of the MSc dissertation of Teresa G. Yañez-Rivera. This work was partially supported by, SEP-UJAT OP/PIFI-2012-27MSU0018V-07-01. We express our sincere appreciation to all participants. We thank BSc Maria del Rocío López-Guevara and BSc Martha Alicia Vidal Castillo for carrying out some biochemical determinations and Carlos Garcia Vazquez for his valuable help formatting the manuscript.

\section{Author details}

${ }^{1}$ Departamento de Cardiología, Hospital General de Zona 46, Instituto Mexicano del Seguro Social (IMSS), Villahermosa, Tabasco, Mexico. Departamento de Cardiología, Hospital Regional de Alta Especialidad "Dr. Juan Graham Casasús", Villahermosa, Tabasco, Mexico. ${ }^{3}$ Centro de Investigación y Posgrado, DACS, Universidad Juárez Autónoma de Tabasco (UJAT), Villahermosa, Tabasco, Mexico. ${ }^{4}$ Coordinación de Investigación, Centro Médico Nacional Siglo XXI, IMSS, Mexico City, México.

Received: 12 June 2014 Accepted: 26 August 2014

Published: 8 September 2014

\section{References}

1. Yusuf S, Hawken S, Ônpuu S, Bautista L, Franzosi MG, Commerford P, Lang CC, Rumboldt Z, Onen CL, Lisheng L, Tanomsup S, Wangai P, Razak F, Sharma AM, Anand SS: Obesity and the risk of myocardial infarction in 27,000 participants from 52 countries: a case-control study. Lancet 2005, 366:1640-1649.

2. Janssen I, Katzmarzyk PT, Ross R: Body mass index, waist circumference, and health risk: evidence in support of current national institutes of health guidelines. Arch Intern Med 2002, 162:2074-2079.

3. Kershaw EE, Flier JS: Adipose tissue as an endocrine organ. J Clin Endocrinol Metab 2004, 89:2548-2556.

4. Shibata R, Ouchi N, Murohara T: Adiponectin and cardiovascular disease. Circ J 2009, 73:608-614.

5. Rothenbacher D, Brenner H, Marz W, Koenig W: Adiponectin, risk of coronary heart disease and correlations with cardiovascular risk markers. Eur Heart J 2005, 26:1640-1646.

6. Laughlin GA, Barrett-Connor E, May S, Langenberg C: Association of adiponectin with coronary heart disease and mortality: the Rancho Bernardo study. Am J Epidemiol 2007, 165:164-174.

7. Mazurek T, Zhang L, Zalewski A, Mannion JD, Diehl JT, Arafat H, Sarov-Blat L, O'Brien S, Keiper EA, Johnson AG, Martin J, Goldstein BJ, Shi Y: Human epicardial adipose tissue is a source of inflammatory mediators. Circulation 2003, 108:2460-2466.

8. Cheng KH, Chu CS, Lee KT, Lin TH, Hsieh CC, Chiu CC, Voon WC, Sheu SH, Lai WT: Adipocytokines and proinflammatory mediators from abdominal and epicardial adipose tissue in patients with coronary artery disease. Int J Obes 2007, 32:268-274.

9. Zhou Y, Wei Y, Wang L, Wang X, Du X, Sun Z, Dong N, Chen X: Decreased adiponectin and increased inflammation expression in epicardial adipose tissue in coronary artery disease. Cardiovasc Diabetol 2011, 10:2.

10. Baker A, da Silva N, Quinn D, Harte A, Pagano D, Bonser R, Kumar S, McTernan P: Human epicardial adipose tissue expresses a pathogenic profile of adipocytokines in patients with cardiovascular disease. Cardiovasc Diabetol 2006, 5:1.

11. Chaldakov GN, Stankulov IS, Aloe L: Subepicardial adipose tissue in human coronary atherosclerosis: another neglected phenomenon. Atherosclerosis 2001, 154:237-238.
12. Xu Y, Cheng $X$, Hong $K$, Huang C, Wan L: How to interpret epicardial adipose tissue as a cause of coronary artery disease: a meta-analysis. Coronary Artery Dis 2012, 23:227-233.

13. Katzmarzyk PT, Bray GA, Greenway FL, Johnson WD, Newton RL, Ravussin E, Ryan DH, Smith SR, Bouchard C: Racial differences in abdominal depot-specific adiposity in white and African American adults. Am J Clin Nutr 2010, 91:7-15.

14. Willens HJ, Gomez-Marin O, Chirinos JA, Goldberg R, Lowery MH, lacobellis G: Comparison of epicardial and pericardial fat thickness assessed by echocardiography in African American and non-Hispanic White men: a pilot study. Ethn Dis 2008, 18:311-316.

15. lacobellis G, Willens HJ: Echocardiographic epicardial Fat: a review of research and clinical applications. J Am Soc Echocardiogr 2009, 22:1311-1319.

16. Alberti KG, Eckel RH, Grundy SM, Zimmet PZ, Cleeman Jl, Donato KA, Fruchart JC, James WP, Loria CM, Smith SC Jr: Harmonizing the metabolic syndrome: a joint interim statement of the International Diabetes Federation Task Force on Epidemiology and Prevention; National Heart, Lung, and Blood Institute; American Heart Association; World Heart Federation; International Atherosclerosis Society; and International Association for the Study of Obesity. Circulation 2009, 120:1640-1645.

17. lacobellis G, Assael F, Ribaudo MC, Zappaterreno A, Alessi G, Di Mario U, Leonetti F: Epicardial Fat from echocardiography: a New method for visceral adipose tissue prediction. Obes Res 2003, 11:304-310.

18. Ahn S-G, Lim H-S, Joe D-Y, Kang S-J, Choi B-J, Choi S-Y, Yoon M-H, Hwang G-S, Tahk S-J, Shin J-H: Relationship of epicardial adipose tissue by echocardiography to coronary artery disease. Heart 2008, 94:e7.

19. Mustelier JV, Rego JO, Gonzalez AG, Sarmiento JC, Riveron BV: Echocardiographic parameters of epicardial fat deposition and its relation to coronary artery disease. Arq Bras Cardiol 2011, 97:122-129.

20. Jeong JW, Jeong MH, Yun KH, Oh SK, Park EM, Kim YK, Rhee SJ, Lee EM, Lee J, Yoo NJ, Kim NH, Park JC: Echocardiographic epicardial fat thickness and coronary artery disease. Circ J 2007, 71:536-539.

21. lacobellis G, Willens HJ, Barbaro G, Sharma AM: Threshold values of high-risk echocardiographic epicardial fat thickness. Obesity (Silver Spring) 2008, 16:887-892.

22. Barquera S, Campos-Nonato I, Hernández-Barrera L, Pedroza-Tobías A, Rivera-Dommarco J: Prevalencia de obesidad en adultos mexicanos, ENSANUT 2012. Salud Publica Mex 2013, 55:S151-S160.

23. Eroglu S, Sade LE, Yildirir A, Bal U, Ozbicer S, Ozgul AS, Bozbas H, Aydinalp A, Muderrisoglu H: Epicardial adipose tissue thickness by echocardiography is a marker for the presence and severity of coronary artery disease. Nutr Metab Cardiovasc Dis 2009, 19:211-217.

24. Maeda K, Okubo K, Shimomura I, Mizuno K, Matsuzawa Y, Matsubara K: Analysis of an expression profile of genes in the human adipose tissue. Gene 1997, 190:227-235.

25. Chaldakov GN, Beltowsky J, Ghenev PI, Fiore M, Panayotov P, Rancic G, Aloe L: Adipoparacrinology-vascular periadventitial adipose tissue (tunica adiposa) as an example. Cell Biol Int 2012, 36:327-330.

26. Yun KH, Rhee SJ, Yoo NJ, Oh SK, Kim NH, Jeong JW, Park DS, Park HY: Relationship between the Echocardiographic Epicardial Adipose Tissue Thickness and Serum Adiponectin in Patients with Angina. J CardiovasC Ultrasound 2009, 17:121-126.

27. Hirata Y, Kurobe H, Akaike M, Chikugo F, Hori T, Bando Y, Nishio C, Higashida M, Nakaya Y, Kitagawa T, Sata M: Enhanced inflammation in epicardial fat in patients with coronary artery disease. Int Heart J 2011, 52:139-142.

28. lacobellis G, di Gioia CR, Cotesta D, Petramala L, Travaglini C, De Santis V, Vitale $D$, Tritapepe $L$, Letizia $C$ : Epicardial adipose tissue adiponectin expression is related to intracoronary adiponectin levels. Horm Metabol Res 2009, 41:227-231.

\section{doi:10.1186/1476-7120-12-35}

Cite this article as: Yañez-Rivera et al:: Relationship between epicardial adipose tissue, coronary artery disease and adiponectin in a Mexican population. Cardiovascular Ultrasound 2014 12:35. 